\title{
Peningkatan Pengetahuan Ibu dalam Deteksi Dini dan Pencegahan Stunting pada Balita
}

\author{
Ratih Sakti Prastiwi $^{1}$, Meyliya Qudriani ${ }^{2}$, Istiqomah Dwi Andari ${ }^{3}$ \\ 1,2,3 Politeknik Harapan Bersama, J1. Mataram No.9, Kel. Pesurungan lor, Kel. Pesurungan Lor, \\ Pesurungan Lor, Kec. Margadana, Kota Tegal, Jawa Tengah 52147 \\ Email: ratih.sakti@poltektegala.c.id ${ }^{1}$
}

\begin{abstract}
ABSTRAK
Stunting masih menjadi masalah besar di dunia, meskipun dalam satu decade sudah mengalami penurunan namun prevalensinya masih cukup besar. Stunting yang tidak tertangani memiliki dampak panjang pada kehidupan anak. Adanya pandemic COVID-19 menambah beban dalam pelaksanaan penanganan stunting. Oleh karena itu ibu menjadi sasaran yang tepat untuk membantu mencegah terjadinya stunting pada anak. Ibu sebagai pengasuh utama anak harus memiliki informasi yang cukup untuk melakukan deteksi dini dan pencegahan stunting. Oleh karena itu perlu adanya upaya peningkatan pengetahuan ibu terkait pencegahan stunting. Pengabdian masyarakat dilakukan melalui pemberian pendidikan kesehatan dan praktek pembuatan MPASI. Kegiatan dilaksanakan pada 13 November 2020 melibatkan 35 ibu yang memiliki balita. Peserta mendapatkan materi terkait stunting dan pencegahannya. Ibu juga diajarkan mengenai deteksi dini stunting melalui cara membaca KMS. Tim juga melakukan demonstrasi memasak makanan untuk anak dimulai dari teknik pengolahan bahan makanan serta teknik memasak yang benar sehingga nutrisi makanan tetap terjaga. Teknik ceramah didukung dengan demonstrasi sangat membantu peserta dalam memahami informasi yang diberikan. Agar tercapai tujuan penurunan angka stunting maka perlu dilakukan pemberian pendidikan kesehatan lebih sering agar informasi yang didapatkan oleh ibu lebih banyak. Dengan pengetahuan yang tepat dan benar maka secara langsung dapat merubah sikap dan perilaku ibu menjadi lebih sehat.
\end{abstract}

Kata kunci: Stunting, Balita, Pendidikan Kesehatan

\begin{abstract}
Stunting is still a significant problem in the world. Although in a decade it had decreased, its prevalence was still quite large. Untreated stunting has a lasting impact on a child's life. The existence of the COVID-19 pandemic adds to the burden in the implementation of handling stunting. Therefore, mothers are the right person to help prevent stunting in children. Mothers, as the primary caregivers of children, must have sufficient information to detect and prevent stunting. Therefore, it is necessary to increase the knowledge of mothers related to stunting prevention. Community service was carried out through providing health education and practice of making complementary foods. The activity was held on November 13, 2020, involving 35 mothers who have toddlers. Participants received material related to stunting and its prevention. Participants also taught about early detection of stunting by reading Health Card. The team also conducted a cooking demonstration starting with food processing techniques and proper cooking techniques to maintain food nutrition. The lecture technique supported by demonstrations helped the participants understand the information provided. Health education to reduce the stunting rate needs to be done more frequently so that mothers can obtain more information. The proper and correct knowledge can directly change the mother's attitude and behavior to become healthier.
\end{abstract}

Keywords: Stunting, Children Under Five, Health Education 


\section{PENDAHULUAN}

Stunting merupakan cerminan kondisi status pertumbuhan linier yang buruk ditunjukkan dari tinggi badan untuk usia kurang dari (-2) standar deviasi dari median standar pertumbuhan anak yang ditetapkan oleh WHO (World Health Organization). Kondisi ini jika tidak segera tertangani dapat menyebabkan dampak jangka panjang seperti gangguan perkembangan, penurunan kemampuan kognitif, resiko infeksi meningkat serta saat usia dewasa dapat mengalami penurunan produktivitas yang secara langsung akan mempengaruhi kemampuan ekonomi (Beal dkk., 2018).

Penurunan kejadian stunting merupakan tujuan ke-enam dari The Global Nutrition Target pada tahun 2025. Tidak hanya itu, penurunan stunting juga merupakan indikator kedua Sustainable Development Goal (Beal dkk., 2018). Beberapa literatur menyatakan bahwa dalam satu dekade terakhir stunting telah mengalami penurunan namun angka kejadiannya masih tinggi termasuk di Indonesia (Bhutta dkk., 2020). Kejadian stunting pada tahun 2019 telah mengalami penurunan sebesar 3.13\% namun angka kejadian stunting masih jauh tinggi dibanding dengan target WHO (Latifah dkk., 2020).

Selama masa pandemi COVID-19 berbagai sektor dibatasi ruang geraknya untuk menekan terjadinya penularan COVID-19, begitupula dengan sektor kesehatan. Adanya pembatasan ini mengakibatkan secara langsung penanganan stunting menjadi terhambat. Hal tersebut berpotensi meningkatkan kasus stunting pada anak (Lawaceng dan Rahayu, 2020; UNICEF, 2020). Oleh karena itu perlu adanya upaya untuk mencegah stunting selama pandemi. Candarweni dan Rahayu menyebutkan bahwa masyarakat menjadi aktor penting selama pandemi dalam mencegah stunting. Saat masyarakat memiliki pengetahuan dan informasi akan masalah yang dihadapi, maka masyarakat akan dapat memberdayakan diri untuk memecahkan masalah secara mandiri sebelum ada keterlibatan pihak lain.

\section{METODE}

Kegiatan pengabdian masyarakat ini dilakukan dengan mengangkat tema pencegahan stunting melalui peningkatan pengetahuan ibu terkait stunting dan cara pengolahan makanan yang benar. Kegiatan ini menggunalan metode ceramah dan demonstrasi praktek memasak. Kegiatan ini dilaksanakan bekerjasama dengan Puskesmas Kramat pada tanggal 13 November 2020. Kegiatan ini dibagi menjadi dua sesi, sesi pertama dilakukan dengamn pemberian materi mengenai stunting dan pencegahannya. Sesi kedua tim bersama pihak Puskesmas Kramat mendemonstrasikan cara pengelolaan 
makanan untuk anak yang tepat. Jumlah peserta dalam kegiatan ini sebanyak 35 ibu yang memiliki bayi dan balita.

\section{HASIL, PEMBAHASAN, DAN DAMPAK}

Kegiatan pengabdian masyarakat dilakukan melalui pendidikan kesehatan dalam kelas gizi yang diselenggarakan oleh Puskesmas Kramat. Kelas gizi merupakan salah satu program Puskesmas Kramat yang dilaksanakan satu bulan sekali dari pukul 09.00-12.00 WIB. Dalam kegiatan ini, tim diberikan kesempatan untuk memberikan materi tentang deteksi dini stunting dan upaya pencegahan melalui intervensi gizi spesifik. Kegiatan ini melibatkan peserta dari ibu-ibu yang memiliki anak usia balita. Sasaran tersebut dipilih karena balita merupakan usia yang rentan terdeteksi stunting. Selainitu, Ibu sebagai pengasuh utama dalam memastikan anak tidak mengalami stunting, baik melalui deteksi dini maupun pemenuhan gizi saat di rumah (Sary, 2020).

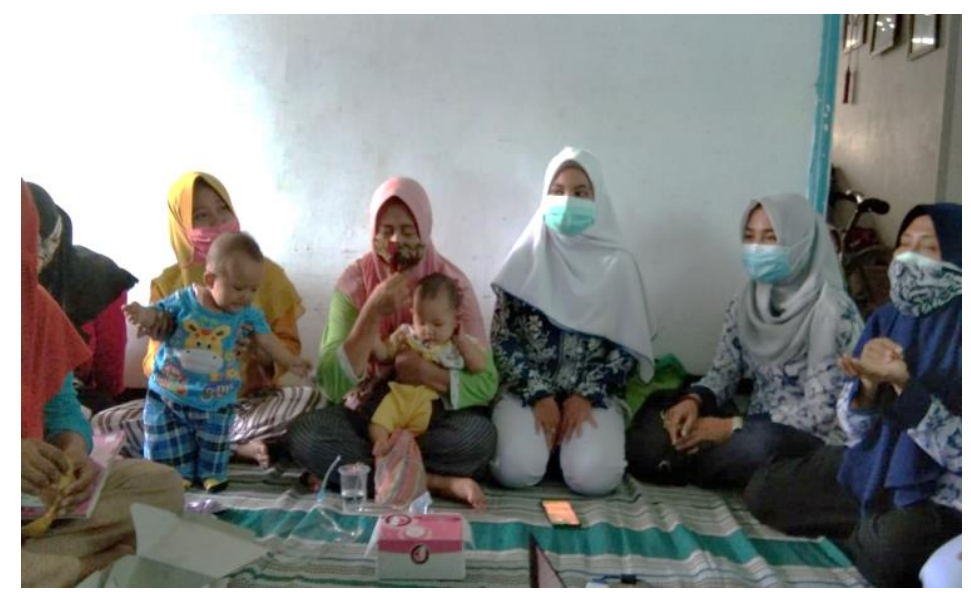

Gambar 1. Pemberian Materi Stunting oleh Tim

Ibu diberikan informasi mengenai definisi stunting dimana anak akan dikatakan stunting apabila pertumbuhan berat badan dan tinggi badang kurang dari -2 deviasi menurut standar WHO. Ibu diajarkan membaca KMS untuk membantu ibu memantau perkembangan anaknya (Maulida dkk., 2019). Pemberian informasi yang tepat akan membantu meningkatkan kognitif dan afektif ibu sehingga muncul kesadaran dan kemauan untuk merubah perilakunya menjadi lebih positif (Huriah dkk., 2020).

Dalam mencegah stunting perlu adanya intervensi gizi spesifik pada 1000 hari pertama kehidupan salah satunya pada periode anak usia 0-6 bulan dan 7-23 bulan. Untuk mencegah stunting secara efektif maka intervensi gizi yang diberikan harus disesuaikan usia anak. Intervensi gizi yang ideal bagi anak usia 0-6 bulan yaitu dengan pemberian ASI secara eksklusif. Sedangkan intervensi pada anak usia 7-23 bulan melalui pemberian PMT yang sesuai dengan usia anak, pemberian garam beryodium, pemberian ASI Eksklusif sampai 2 tahun, imunisasi, pemberian suplemen zink, fortifikasi zat besi dalam makanan, pemberian obat cacing, pemberian vitamin A 
sebanyak 2 kali. Apabila anak memiliki penyakit gizi buruk makan penanganan difokuskan pada tata laksana gizi buruk (Sary, 2020).

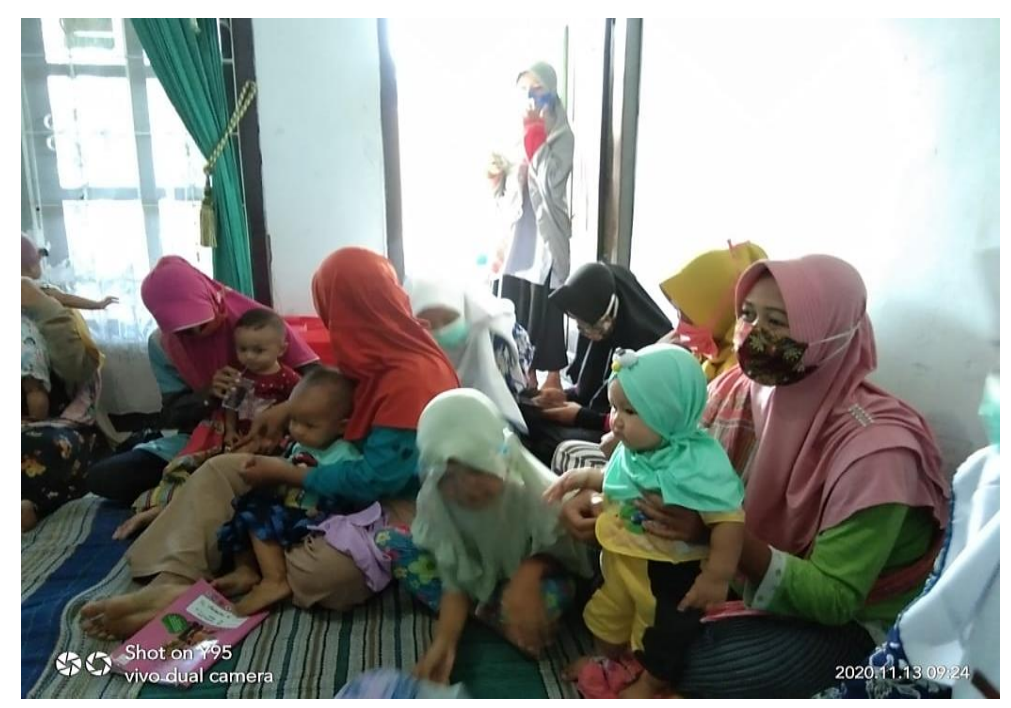

Gambar 2 Sesi Tanya Jawab

Pemberian pendidikan kesehatan menggunakan metode ceramah merupakan metode yang paling sering dilakukan. Metode ini juga memiliki kekurangan yaitu mudah menimbulkan kejenugan peserta, serta peserta cenderung lebih pasif. Oleh karena itu, untuk meningkatkan keaktifan peserta selama materi tim memberikan pertanyaan dan diskusi. Dengan adanya interaksi aktif, konsentrasi peserta juga akan meningkat sehingga penerimaan informasi menjadi lebih baik (Prastiwi dkk., 2017). Metode lain yang dilakukan adalah dengan melakukan kegiatan praktek memasak MPASI. Dalam kegiatan ini, ibu juga diajarkan memasak MPASI yang benar dari pihak Puskesmas Kramat dimulai dari teknik mengelola bahan makanan yang tepat seperti teknik mencuci dan memotong bahan makanan. Peserta memperhatikan secara langsung teknik memasak yang dipraktekkan oleh tim. Dampak dari pemberian demonstasi memasak ini adalah peserta lebih memahami cara mengelola makanan yang tepat agar nutrisi anak terjaga. Metode ini memiliki keunggulan mudah dipahami peserta. Peserta dirangsang untuk mengamati dan dapat mempraktekkan sendiri. Metode ini merangsang semua indra sehingga lebih mudah dipahami dan diketahui mampu meningkatkan kemampuan peserta (Lestari dkk., 2020).

\section{SIMPULAN}

Pemberian pendidikan kesehatan mengenai deteksi dini dan pencegahan stunting kepada ibu merupakan strategi yang tepat. Ibu sebagai pengasuh utama memiliki kendali untuk memonitor pertumbuhan anaknya dan menentukan metode dan menu makanan yang tepat bagi anak. Pemberian pendidikan kesehatan perlu dilakukan lebih sering agar keinginan ibu untuk mencari informasi semakin besar dan secara langsung mampu merubah sikap dan perilaku ibu menjadi lebih positif. 


\section{UCAPAN TERIMAKASIH}

Tim mengucapkan terimakasih kepada Puskesmas Kramat yang telah berkenan bekerjasama dengan Tim Pelaksana dalam pelaksanaan Kelas Gizi. Tim juga mengucapkan terimakasih atas support dari Politeknik Harapan Bersama untuk kelancaran pelaksanaan kegiatan ini.

\section{DAFTAR PUSTAKA}

Beal, T., Tumilowicz, A., Sutrisna, A., Izwardy, D., dan Neufeld, L. M. (2018). A Review of Child Stunting Determinants in Indonesia. Maternal dan Child Nutrition, 14(4), e12617. https://doi.org/10.1111/mcn.12617

Bhutta, Z. A., Akseer, N., Keats, E. C., Vaivada, T., Baker, S., Horton, S. E., Katz, J., Menon, P., Piwoz, E., Shekar, M., Victora, C., dan Black, R. (2020). How countries can reduce child stunting at scale: lessons from exemplar countries. The American Journal of Clinical Nutrition, 112(Supplement_2), 894S-904S. https://doi.org/10.1093/ajcn/nqaa153

Huriah, T., Larasati, Y., Tiwi Sudyasih, Sutantri, dan Susyanto, B. E. (2020). Pendidikan Ibu Berbasis Masyarakat (PIBM) dalam Meningkatkan Pengetahuan dan Sikap Pemenuhan Gizi Balita Stunting. Jurnal Solma, 9(2).

Latifah, U., Sakti Prastiwi, R., dan Baroroh, U. (2020). The Responsive Feeding Behavior and Stunting Incident on Toddlers. Jurnal Kebidanan, 10(2), 143-148. https://doi.org/10.31983/jkb.v10i2.6286

Lawaceng, C., dan Rahayu, A. Y. S. (2020). Tantangan Pencegahan Stunting pada Era Adaptasi Baru "New Normal" melalui Pemberdayaan Masyarakat di Kabupaten Pandeglang. In Jurnal Kebijakan Kesehatan Indonesia: JKKI (Vol. 9, Issue 3). https://doi.org/10.22146/JKKI.57781

Lestari, P. I., Mansur, H., dan Wandi. (2020). The Influence Of Health Education Methods Of Demonstration About Breast Self-Examination Of The Ability To Realize In Young Women Senior High School Diponegoro Dampit. Jurnal Pendidikan Kesehatan, 9(1).

Maulida, I., Prastiwi, R. S., dan Chikmah, A. M. (2019). Studi Kasus: Tanda dan Gejala Citomegalovirus pada Balita. Siklus : Journal Research Midwifery Politeknik Tegal, $8(1), 21$.

Prastiwi, R., Qudriani, M., Ludha, N., dan Arsita, R. (2017). Peningkatan Persepsi Kecukupan ASI Pada Ibu Menyusui. Jurnal Pengabdian Masyarakat Progresif Humanis Brainstorming, 1(1), 42-48. https://doi.org/10.30591/japhb.v1i1.687

Sary, Y. N. E. (2020). Pendidikan Kesehatan kepada Nenek Pengasuh dalam Mencegah 
Stunting Anak Usia 36 Bulan di Daerah Pesisir Pantai. Pratama Widya: Jurnal Pendidikan Anak Usia Dini, 26158396. https://doi.org/10.25078/PW.V5I2.1442

UNICEF. (2020). COVID-19 dan Anak-Anak di Indonesia. 